\title{
Automated Segmentation of Hippocampal Volume: The Next Step in Neuroradiologic Diagnosis of Mesial Temporal Sclerosis
}

1

have read with great interest the article titled "Improved Detection of Subtle Mesial Temporal Sclerosis: Validation of a Commercially Available Software for Automated Segmentation of Hippocampal Volume" by Mettenburg et al. ${ }^{1}$ Mesial temporal sclerosis (MTS) is one of the most common operable causes of drug-resistant epilepsy. As rightly noted by the authors, clinical, electrophysiologic, and radiologic concordance is essential for selecting a patient for epilepsy surgery. With a good sensitivity (89\%), Neuroreader software (https://brainreader.net/p/product/ neuroreader) would definitely improve the pickup rate of mesial temporal sclerosis. Further improvement in the sensitivity to $>95 \%$ would make Neuroreader a reliable tool to aid the radiologist.

Although this was a retrospective study, it would be useful to see the probable clinical impact of Neuroreader in those patients in whom Neuroreader identified the MTS correctly and MTS was missed by the neuroradiologist. The authors could have assessed whether invasive monitoring was performed in those misdiagnosed patients and whether it could have been avoided by the use of Neuroreader.

The burden of drug-resistant epilepsy is large in developing countries. In these countries, temporal lobe seizure operations are performed on the basis of 1.5T MR imaging of the brain. Ahdidan et $\mathrm{al}^{2}$ have shown significant correlation between hippocampal volume quantification by Neuroreader in $1.5 \mathrm{~T}$ and $3 \mathrm{~T}$ MR images. Neuroreader would be useful in developing countries if a 1.5T volumetric acquisition could be used for identifying MTS. This may require a clinical study to determine the validity of Neuroreader on a population different from that in its training data.

The cost of Neuroreader would be an important consideration

http://dx.doi.org/10.3174/ajnr.A6092 for widespread use in developing countries. Desikan et $\mathrm{al}^{3}$ have reported the cost of Neuroreader per study at $\$ 80$, which would cost more than MR imaging of the brain in developing countries. Publically available software like JFL/CL (https://www.nitrc.org/ projects/ashs/; https://sites.google.com/site/hipposubfields/) ${ }^{4}$ and HIPPOSEG (http://niftyweb.cs.ucl.ac.uk/program.php?p=BRAINSTEPS), ${ }^{5}$ though not FDA-approved, would aid in MTS identification and aid the neuroradiologist.

Although there were only 26 patients positive for MTS, the authors have done a commendable statistical analysis and this study plays a vital role in emphasizing the importance of automated segmentation software in aiding neuroradiology reporting and operative decision-making.

\section{REFERENCES}

1. Mettenburg JM, Branstetter BF, Wiley CA, et al. Improved detection of subtle mesial temporal sclerosis: validation of a commercially available software for automated segmentation of hippocampal volume. AJNR Am J Neuroradiol 2019;40:440 - 45 CrossRef Medline

2. Ahdidan J, Raji CA, DeYoe EA, et al. Quantitative neuroimaging software for clinical assessment of hippocampal volumes on MR imaging. J Alzheimers Dis 2016;49:723-32 CrossRef Medline

3. Desikan RS, Rafii MS, Brewer JB, et al. An expanded role for neuroimaging in the evaluation of memory impairment. AJNR Am J Neuroradiol 2013;34:2075-82 CrossRef Medline

4. Hadar PN, Kini LG, Coto C, et al. Clinical validation of automated hippocampal segmentation in temporal lobe epilepsy. Neuroimage Clin 2018;20:1139-47 CrossRef Medline

5. Winston GP, Cardoso MJ, Williams EJ, et al. Automated hippocampal segmentation in patients with epilepsy: available free online. Epilepsia 2013;54:2166-73 CrossRef Medline

(D) N. Damodaran Department of Neurosurgery Mahatma Gandhi Medical College and Research Institute Pondicherry, India 